\title{
Los actos administrativos de destitución según la Ley 29988 y el debido procedimiento administrativo
}

\section{Administrative acts of dismissal according to Law 29988 and due administrative procedure}

\author{
María Marianela Díaz Mendoza ${ }^{1}$
}

\section{RESUMEN}

El objetivo de la investigación fue determinar si los actos administrativos de destitución a los docentes condenados en aplicación de la Ley $\mathrm{N}^{\circ} 29988$ vulneran el debido procedimiento administrativo en la Dirección Regional de Educación Amazonas, 2018. El diseño de la investigación fue no experimental, de modo transversal, de tipo descriptivo-analítico y correlacional. La población muestral estuvo constituida por dieciséis expedientes administrativos; se aplicó la ficha de recojo documental para la recolección de datos de los expedientes administrativos. Se encontró que el $44 \%$ registra sentencia condenatoria consentida o ejecutoriada por el delito de Tráfico Ilícito de Drogas y el 56\% por el delito de Violación a la Libertad Sexual; del total de docentes destituidos en aplicación de la Ley 29988, el 100\% no fueron notificados, consecuentemente, no tuvieron la oportunidad para ejercer su derecho a la defensa, ofrecer y presentar medios probatorios en su defensa, antes de la emisión de la resolución administrativa. Se concluye que los actos administrativos de destitución automática a los docentes condenados en aplicación de la Ley 29988 si vulneraron el debido procedimiento administrativo en la Dirección Regional de Educación Amazonas, 2018.

Palabras clave: Actos administrativos, destitución, debido procedimiento

\begin{abstract}
The objective of the investigation was to determine whether the administrative acts of automatic dismissal of teachers sentenced under Law 29988 violate due administrative procedure in DREA-2018. The research design was non-experimental, cross-sectional, descriptive-analytical and correlational. The population consisted of sixteen administrative files of the Amazonas Regional Directorate of Education corresponding to the year 2018; the sample was made up of the total population; the document collection sheet was applied to collect data from administrative files. It was found that $44 \%$ registered a consensual or enforceable conviction for the crime of Illicit Drug Trafficking and 56\% for the crime of Violation of Sexual Freedom; of the total number of teachers dismissed in application of Law 29988, 100\% were not notified, consequently, they did not have the opportunity to exercise their right to defense, offer and present evidence in their defense, before the issuance of the administrative resolution. It is concluded that the administrative acts of automatic dismissal of teachers sentenced in application of Law 29988 if they violated the due administrative procedure in DREA-2018.
\end{abstract}

Keywords: Administrative acts, removal, due process

${ }^{1}$ Bachiller en Derecho de la Universidad Católica Santo Toribio de Mogrovejo. Correo electrónico: mariamarianelad@gmail.com 


\section{INTRODUCCIÓN}

En el Perú, el Estado garantiza que los estudiantes cuenten con profesores con un perfil intachable, en base a valores e integridad absoluta en su actuar, toda vez que, la misión que se les confía resulta ser relevante para la formación de los educandos y de toda la sociedad.

El artículo $13^{\circ}$ de la Constitución Política del Perú señala que la educación tiene como finalidad el desarrollo integral de la persona humana; asimismo, el artículo $4^{\circ}$ del Decreto Ley $N^{\circ}$ 25762, Ley Orgánica del Ministerio de Educación, establece que, corresponde al Ministerio de Educación formular las políticas nacionales en materia de educación en armonía con los planes de desarrollo y la política general del Estado, supervisar y evaluar su cumplimiento, y formular los planes y programas.

El Ministerio de Educación (MINEDU) considera que, no puede ser admitido que docentes que han obtenido sentencia condenatoria consentida o ejecutoriada por los delitos de Terrorismo, Apología de Terrorismo, Violación contra la Libertad Sexual y Tráfico Ilícito de Drogas, se encuentren a cargo de la educación de los niños, niñas y adolescentes; por lo que, con fecha 18 de enero de 2013 publicó la Ley $\mathrm{N}^{\circ}$ 29988 en el Diario Oficial el Peruano, Ley que establece medidas extraordinarias para el personal docente y administrativo de instituciones educativas públicas y privadas, implicado en los delitos antes mencionados y, con fecha 19 de mayo de 2017 se publicó su Reglamento mediante Decreto Supremo Nº04-2017-MINEDU.

Asimismo, con fecha 25 de mayo de 2018, el MINEDU publicó la Norma Técnica denominada "Disposiciones que regulan la aplicación de la Ley N² 29988 y su Reglamento en el MINEDU, DRE y UGEL". En este contexto, el MINEDU y los gobiernos regionales, a través de las Direcciones o Gerencias Regionales de Educación y las Unidades de Gestión Educativa Local de su jurisdicción, en coordinación y con el apoyo de los gobiernos locales, dentro de los 30 días hábiles de iniciado el año escolar, supervisan que ninguna institución educativa cuente con personal que registre sentencia condenatoria consentida o ejecutoriada por los delitos de Terrorismo, Apología de Terrorismo, Violación contra la Libertad Sexual y Tráfico Ilícito de Drogas, en aplicación de la Ley N 29988.

Que, para cumplir con dicha política de estado, la Jefa de la Oficina General de Transparencia, Ética Pública y Anticorrupción (OTEPA) del MINEDU mediante oficio remite a las UGELs y DREs a nivel nacional, la lista de docentes condenados por los delitos antes mencionados, a fin de que estas procedan conforme a sus atribuciones.

Ahora bien, en el año 2018 la Dirección Regional de Educación Amazonas (DREA) ha emitido actos administrativos, en los que resuelve destituir al docente de su cargo de conformidad con lo dispuesto en la Ley $\mathrm{N}^{\circ} 29988$ e inhabilitarlo de manera permanente para el ingreso o reingreso al servicio educativo en instituciones educativas públicas o privadas.

Ante esta realidad problemática, se ha planteado como problema de investigación: ¿Los actos administrativos de destitución automática a los docentes condenados en aplicación de la Ley $\mathrm{N}^{\circ}$ 29988 vulneran el debido procedimiento administrativo en la DREA-2018?; siendo que, para poder responder a dicha interrogante, se ha fijado como objetivo principal: Determinar si los actos administrativos de destitución automática a los docentes condenados en aplicación de la Ley $\mathrm{N}^{\circ}$ 29988 vulneran el debido procedimiento administrativo en la DREA-2018, y como objetivos específicos se han planteado: Analizar la normatividad que regula los actos administrativos de destitución automática a los docentes condenados por los delitos establecidos en la Ley $\mathrm{N}^{\circ} 29988$; analizar la aplicación del debido procedimiento administrativo en los actos administrativos de destitución automática a los docentes condenados por los delitos establecidos en la Ley N 29988 emitidos por la DREA-2018; y, analizar la teoría de los hechos cumplidos en los actos administrativos de destitución automática a los docentes condenados en aplicación de la Ley Nº 29988 emitidos por la DREA-2018.

\section{MATERIAL Y MÉTODO}

La investigación es de tipo cualitativa, la misma que nació con el planteamiento de un problema delimitado y concreto; asimismo, la investigación se ocupó de aspectos específicos externos del objeto de estudio; y, el marco teórico que guía el estudio fue elaborado sobre la base de la revisión de la literatura. (Hernández, Fernández \& Batista, 2010, p.127)

Diseño de la investigación, el término diseño se refirió al plan o estrategia concebida para obtener la información que se desea con el fin de responder al planteamiento del problema (Hernández, Fernández \& Batista, 2014, p. 128).

La presente investigación fue de diseño: no experimental, que consistió en observar los expedientes administrativos sobre destitución a los docentes en aplicación de la Ley 29988, y analizarlo en su estado natural; de modo transversal o transeccional, porque los datos plasmados en los expedientes administrativos se recopilaron en un tiempo único; de tipo descriptivo-analítico, en la presente investigación el interés fue cada variable tomada individualmente; $y$, correlacional, el interés de la investigación fue la relación entre variables.

La población para el desarrollo de la investigación estuvo compuesta por dieciséis expedientes administrativos de la Dirección Regional de 
Educación Amazonas correspondientes al año 2018, y la muestra estuvo compuesta por el total de la población, toda vez que, la población fue pequeña.

La investigación tiene dos variables: Los actos administrativos de destitución según la Ley 29988 y El debido procedimiento administrativo en la DREA-2018.

Los métodos científicos que se utilizaron: deductivo, el cual permitió conocer la realidad global de las variables de estudio, analizando el problema desde lo general hasta llegar a lo específico y confirmar nuestra hipótesis; analítico, el cual permitió realizar el análisis de los resultados obtenidos mediante el uso del instrumento consistente en la ficha de recojo documental; y, argumentativo, el cual permitió comprobar que los actos administrativos de destitución a los docentes en aplicación de la Ley 29988 resulta arbitraria, se discutió las consecuencias de su aplicación, y se llegó a una conclusión crítica, de que la destitución del cargo de docente constituye una situación que a todas luces evidencia una aplicación retroactiva de la Ley infraconstitucional en contravención del principio de la irretroactividad de la Ley, y en grave perjuicio de los derechos fundamentales de los docentes destituidos.

La técnica utilizada fue el análisis documental, para lo cual se utilizó como instrumento la ficha de recojo documental.

\section{RESULTADOS}

Tabla 1. Porcentaje de docentes notificados antes de la emisión de la resolución administrativa de destitución.

\begin{tabular}{ccc}
\hline $\begin{array}{l}\text { Notificación } \\
\text { al docente }\end{array}$ & Cantidad & Porcentaje \\
\hline Sí & 0 & $0 \%$ \\
No & 16 & $100 \%$ \\
\hline Total & 16 & $100 \%$ \\
\hline
\end{tabular}

Tabla 2. Porcentaje de docentes que ejercieron su derecho de defensa antes de la emisión de la resolución administrativa de destitución.

\begin{tabular}{ccc}
\hline $\begin{array}{c}\text { Ejerció su derecho } \\
\text { de defensa }\end{array}$ & Cantidad & Porcentaje \\
\hline Sí & 0 & $0 \%$ \\
No & 16 & $100 \%$ \\
\hline Total & 16 & $100 \%$ \\
\hline
\end{tabular}

Tabla 3. Porcentaje de docentes respecto a la oportunidad para ofrecer medios probatorios en su defensa.

\begin{tabular}{ccc}
\hline $\begin{array}{l}\text { Ofreció medios } \\
\text { probatorios }\end{array}$ & Cantidad & Porcentaje \\
\hline Sí & 0 & $0 \%$ \\
No & 16 & $100 \%$ \\
\hline Total & 16 & $100 \%$ \\
\hline
\end{tabular}

Tabla 4. Porcentaje de delitos por el que fue destituido el docente.

\begin{tabular}{lcc}
\hline Delitos & Cantidad & Porcentaje \\
\hline Terrorismo & 0 & $0 \%$ \\
Apología de Terrorismo & 0 & $0 \%$ \\
$\begin{array}{l}\text { Violación a la Libertad } \\
\text { Sexual }\end{array}$ & 7 & $44 \%$ \\
$\begin{array}{l}\text { Tráfico Ilícito de } \\
\text { Drogas }\end{array}$ & 9 & $56 \%$ \\
\hline Total & 16 & $100 \%$ \\
\hline
\end{tabular}

Tabla 5. Porcentaje de años de la sentencia condenatoria y cumplimiento de la condena del docente destituido.

\begin{tabular}{lccc}
\hline Tipos & Años & Cantidad & Porcentaje \\
\hline $\begin{array}{l}\text { Sentencia } \\
\text { condenatoria }\end{array}$ & $1985-2005$ & 16 & $100 \%$ \\
$\begin{array}{l}\text { Cumplimiento } \\
\text { de la condena }\end{array}$ & $1985-2010$ & 16 & $100 \%$ \\
\hline Total & & 16 & $100 \%$ \\
\hline
\end{tabular}

Tabla 6. Porcentaje de docentes según ejercicio docente al momento de ser condenados.

\begin{tabular}{ccc}
\hline $\begin{array}{l}\text { Ejercía el cargo } \\
\text { de docente }\end{array}$ & Cantidad & Porcentaje \\
\hline Sí & 4 & $25 \%$ \\
No & 12 & $75 \%$ \\
\hline Total & 16 & $100 \%$ \\
\hline
\end{tabular}

\section{DISCUSIÓN}

De acuerdo a Villacreses (2015), en su tesis titulada: El principio de interdicción de la arbitrariedad, en la emisión de actos administrativos de la administración pública, a la luz de la Constitución de la República 2008. Concluye que: El respeto del debido proceso, en el desarrollo del procedimiento administrativo previo a la emisión de todo acto administrativo, el derecho de defensa, el derecho a ofrecer medios probatorios, la motivación y debida argumentación jurídica, implican no solo garantías para el administrado, sino también persiguen garantizar la juridicidad del obrar administrativo, y que a través de aquello, se alcancen los cometidos públicos planteados y se respete la razonabilidad. E1 procedimiento adminis trativo tiene como fin la producción de un acto administrativo, si el procedimiento administrativo está viciado, el acto administrativo también lo estará. La observancia del procedimiento administrativo es ineludible. (pp. 9093); sin embargo de los resultados obtenidos en la 
presente investigación se obtuvo que, antes de la emisión del acto administrativo de destitución a los docentes en aplicación de la Ley $\mathrm{N}^{\circ} 29988$, al 100\% no se les notificó (tabla 1), por lo tanto no tuvieron la oportunidad de ejercer su derecho de defensa (tabla 2) y ofrecer medios probatorios en su defensa (tabla 3 ). Por consiguiente, los actos administrativos de destitución a los docentes condenados en aplicación de la Ley $\mathrm{N}^{\circ} 29988$ no han respetado el principioderecho del debido procedimiento administrativo, el mismo que concede a los administrados derechos y garantías implícitos a un procedimiento regular y justo; por lo que, se exige que la administración pública observe este principio-derecho en la tramitación de los procedimientos administrativos que conducen a la creación, modificación o extinción de un derecho o a la imposición de una obligación o sanción. (MINJUS, 2013, p.15).

Asimismo conforme lo establece el Tribunal Constitucional, el ejercicio de la potestad administrativa debe observar lo dispuesto por la Ley del Procedimiento Administrativo General, ley marco que regula los alcances de la actuación administrativa, que en su artículo IV del Título Preliminar consagra, entre otros, el derecho al debido procedimiento administrativo, el cual determina que los administrados gozan de todos los derechos y garantías, como el derecho a exponer sus argumentos, a ofrecer y reproducir pruebas y a obtener una decisión motivada y fundamentada en derecho. (Sentencia recaída en el Expediente $\mathrm{N}^{\circ}$ 04225-2006-PA/TC, F.J. 6)

Estando a los resultados ya mencionados, concordamos con los señalado por Vidal (2017), en su tesis titulada: "Procedimientos administrativos y su influencia en los actos administrativos en los trabajadores del Decreto Legislativo 276 del Gobierno Regional de Ancash, 2017', para obtener el grado académico de Maestra en Gestión Pública, concluyó: (...) que un procedimiento administrativo poco eficiente dará resultado a la emisión de un acto administrativo con causales de nulidad; por lo que resulta importante que los funcionarios y servidores conozcan los actos normativos como las leyes del derecho administrativo y así desarrollar un procedimiento administrativo eficiente y por consiguiente se emita un acto administrativo conforme a ley. (p. 77)

De los docentes destituidos en aplicación de la Ley $\mathrm{N}^{\circ} 29988$, el $56 \%$ registra sentencia condenatoria por el delito de Tráfico Ilícito de Drogas y el $44 \%$ por el delito de Violación a la Libertad Sexual (tabla 4); asimismo, el $100 \%$ de los docentes destituidos en aplicación de la Ley $\mathrm{N}^{\circ} 29988$ fueron condenados entre los años 1985 a 2005 y cumplieron su condena entre los años de 1985 a 2010 (tabla 5); Ahora bien, cabe precisar que no se realizará una comparación con otras investigaciones, toda vez que, no se ha encontrado investigaciones relacionadas a la Ley $\mathrm{N}^{\circ}$ 29988; por lo tanto, estos resultados se discutirá con la normativa que regula la destitución de los docentes, esto es con la Ley $\mathrm{N}^{\circ} 29988$ publicada con fecha 18 de enero de 2013, la misma que establece medidas extraordinarias para el personal docente y administrativo de instituciones educativas públicas y privadas, implicado en los delitos de Terrorismo, Apología de Terrorismo, Tráfico Ilícito de Drogas y Violación a la Libertad Sexual, y con su Reglamento publicado el 19 de mayo de 2017; asimismo, de conformidad con el artículo $103^{\circ}$ de nuestra Constitución, artículo III del Título Preliminar y artículo $2121^{\circ}$ del Código Civil, que establecen que nuestro sistema jurídico se rige por la teoría de los hechos cumplidos (excepto en materia penal cuando favorece al reo), de modo que la norma se aplica a las consecuencias y situaciones jurídicas existentes; no obstante, la Dirección Regional de Educación Amazonas en el año 2018 ha aplicado la Ley $\mathrm{N}^{\circ}$ 29988 y su Reglamento a situaciones jurídicas pasadas, es decir, a docentes que han sido condenados y que cumplieron su condena, muchos años antes de la publicación y entrada en vigencia de la referida Ley y su Reglamento; es más, el 75\% no ejercían el cargo de docente (tabla 6).

De esta manera, se establece que la destitución de los docentes en aplicación de la Ley Nº 29988 constituye una situación que evidencia una aplicación retroactiva de la Ley infraconstitucional en contravención del principio de la irretroactividad de la Ley, y en grave perjuicio de los derechos fundamentales de los docentes que registran condenada por los delitos de Violación a la Libertad Sexual y Tráfico Ilícito de Drogas; por lo que, ante una realidad tan singular como la descrita en la presente investigación, no resulta razonable la aplicación retroactiva de la Ley y su Reglamento en perjuicio de los derechos fundamentales de los docentes que registran condena por los delitos de Violación a la Libertad Sexual y Tráfico Ilícito de Drogas.

\section{CONCLUSIONES}

De la presente investigación se obtuvo que, antes de la emisión del acto administrativo de destitución a los docentes en aplicación de la Ley N²9988, al 100\% no se les notificó (tabla 1), por lo tanto no tuvieron la oportunidad de ejercer su derecho de defensa (tabla 2) y ofrecer medios probatorios en su defensa (tabla 3); en tal sentido, los actos administrativos de destitución automática a los docentes condenados en aplicación de la Ley $N^{\circ} 29988$ sí han vulnerado el debido procedimiento administrativo en la Dirección Regional de Educación Amazonas en el año2018.

De los docentes destituidos en aplicación de la Ley $\mathrm{N}^{\circ} 29988$, el 56\% registra sentencia condenatoria por 
el delito de Tráfico Ilícito de Drogas y el 44\% por el delito de Violación a la Libertad Sexual (tabla 4); asimismo, el $100 \%$ de los docentes destituidos en aplicación de la Ley $\mathrm{N}^{\circ} 29988$ fueron condenados entre los años 1985 a 2005 y cumplieron su condena entre los años de 1985 a 2010 (tabla 5); sin embargo, la Dirección Regional de Educación Amazonas en el año 2018 ha aplicado la Ley $\mathrm{N}^{\circ} 29988$ y su Reglamento a docentes que han sido condenados y cumplieron su condena, muchos años antes de la publicación y entrada en vigencia de la referida normativa, vulnerando la teoría de los hechos cumplidos que rige nuestro Ordenamiento Jurídico.

De los docentes destituidos en aplicación de la Ley $\mathrm{N}^{\circ}$ 29988, el 75\% no ejercía el cargo de docente (tabla 6); empero, los actos administrativos de destitución emitidos por la Dirección Regional de Educación Amazonas en el año 2018 se sustentan en la situación jurídica de la "condena", sin haber tenido en cuenta que dicha situación jurídica se ha producido cuando no ejercían el cargo de docente.

\section{REFERENCIAS BIBLIOGRÁFICAS}

Constitución Política del Perú de 1993.

Decreto Supremo $\mathrm{N}^{\circ}$ 004-2017-MINEDU, que aprueba el Reglamento de la Ley N 29988. Publicado el 19 de mayo de 2017.

Expediente $\mathrm{N}^{\circ}$ 04225-2006-PA/TC

Hernández, R., Fernández, G., \& Baptista, M. (2014). Metodología de la investigación. Mexicana.

Ley $\mathrm{N}^{\circ}$ 29988, Ley establece medidas extraordinarias para el personal docente y administrativo de instituciones educativas públicas y privadas, implicado en delitos de terrorismo, apología de terrorismo, delitos de violación a la libertad sexual y delitos de tráfico ilícito de drogas. Publicada el 18 de enero de 2013.

MINJUS, (2013). Guía sobre la aplicación del Principio-Derecho del Debido Proceso en los procedimientos administrativos.

Resolución Ministerial N²41-2018-MINEDU, que aprueba la Norma Técnica denominada "Disposiciones que regulan la aplicación de la Ley $N^{\circ} 29988$ y su reglamento en el MINEDU, DRE y UGEL", publicada el $22 \mathrm{de}$ mayo de 2018 .

Rubio, M. (2007). Aplicación de la norma jurídica en el tiempo. Fondo Editorial. Pontifica Universidad Católica del Perú.
Vidal, J. (2017). Procedimientos administrativos y su influencia en los actos administrativos en los trabajadores del Decreto Legislativo 276 del Gobierno Regional de Ancash, 2017 [Tesis de maestría, Universidad Cesar Vallejo]. A r c h i v d i g i t a l. http://repositorio.ucv.edu.pe/handle/20.500. $12692 / 12068$ ?locale-attribute $=$ en

Villacreses, J. (2015). Principio de interdicción de la arbitrariedad, en la emisión de los actos administrativos de la administración pública, a la luz de la Constitución de la Republica 2008 [Tesis de maestría, Universidad Andina Simón Bolívar]. Archivo digital. http://hdl.handle.net/10644/4392. 